\title{
Debate
}

\section{Dealing with scientific fraud: a proposal}

According to a recent Canadian Broadcasting Corporation (CBC) documentary about Dr Ranjit Chandra ${ }^{1}$, there are at least 10 [scientific articles by Chandra] that are either fraudulent or highly suspicious'. These articles were published over 13 years. It does not reflect well on the scientific community that the problem lasted so long and grew so large. How might things be improved?

If you suspect a journal article is fraudulent, you can either submit (for publication) a letter to the journal where it appeared, explaining your suspicion; or contact authorities - perhaps the employer of the author or the funding agency. Which is more effective?

The CBC documentary was the end result of several events:

1. A 2001 article by Chandra in Nutrition reported that a nutritional supplement greatly improved the cognitive functioning of elderly persons ${ }^{2}$.

2. Susan Shenkin et al. wrote to Nutrition questioning certain features of the paper ${ }^{3}$. Their letter was published in 2002, along with Chandra's reply ${ }^{4}$.

3. Chandra's research was described in the New York Times $^{5}$. This attracted the attention of Saul Sternberg and me. When we read the article carefully, we found many suspicious features. We asked Chandra about them. An assistant of his replied that there had been a naming error in the article - 'SE' (standard error) should have been 'SD' (standard deviation). This eliminated one questionable feature but created several more. We wrote to Chandra again but got no reply. So we wrote to Nutrition. Our letter ${ }^{6}$ was published in 2003 along with Chandra's reply ${ }^{7}$.

4. Kenneth Carpenter, a retired professor of nutrition at my university, learned of our questions about the 2001 article. This led him to re-examine a 1992 article by Chandra ${ }^{8}$ based on the same study. He found several problems. The three of us wrote a letter to the Lancet, where the 1992 article was published, raising questions about it. Our letter ${ }^{9}$ was published in 2003, along with Chandra's reply ${ }^{10}$.

5. The Nutrition and Lancet letters apparently caused the British Medical Journal (BMJ) to weigh in. In 2004, a BMJ staff writer wrote that the paper published in Nutrition had previously been submitted to the $B M J^{11}$. According to one reviewer, it had all the hallmarks of being entirely invented'. A few issues later, Chandra replied ${ }^{12}$.

6. A friend of mine brought the Nutrition letter by Sternberg and me to the attention of a journalist, Jill
Mahoney, who wrote about it in a prominent Canadian newspaper ${ }^{13}$. This and other news stories ${ }^{14-16}$, as well as retraction of the 2001 study $^{17}$, led to the CBC documentary $^{1}$, which made several new points relevant to the question of whether Chandra committed scientific fraud, such as the observations of Mark Masor and Marilyn Harvey. The CBC offered Chandra the opportunity to reply but he declined.

The effect of all this is that anyone with library and Internet access can learn that serious questions have been raised about several of Chandra's papers, the basis of these questions and Chandra's answers. He or she can decide if the suspect papers are likely to be accurate - and can draw conclusions about the rest of Chandra's work as well.

Compare this with what happened in several other cases when the other possible action was taken: contacting authorities.

Example 1. In the 1980s, I was sent a preprint of a paper that used a research method with which I was very familiar. The results were so different from my experience I knew they were wrong. I wrote to one of the authors pointing out the problem. Like Chandra, he replied it was a nomenclature error: the measure of variability was incorrect. However, there remained several other reasons why the paper was probably false. I wrote to the National Institutes of Health (NIH), the funding agency, stating my concerns. They wrote to the university where the research had been done. The university's dean of research interviewed one of the authors, who told him the paper was accurate. Based on this, the university dismissed my concerns. When the NIH told me about this, I complained that the raw data had not been examined. As a result, the NIH contacted the university again. The university set up a committee that asked the authors to supply data. They were given computer media. The committee noted that this media contained at least a little bit of data. Based on this, they concluded I was wrong. 'When this is over, only one of us will remain in science', one of the authors told me.

Example 2. In 1989, according to the CBC documentary $^{1}$, Marilyn Harvey, a nurse who recruited subjects for Dr Chandra, suspected data fabrication in a publication by Chandra. She told administrators at Memorial University of Newfoundland (Chandra's employer) of her suspicion. Although a committee concluded that her suspicion was correct, Chandra was not fired. A recent press release from 
Memorial University ${ }^{18}$ stated, 'The vice-presidents were unable to secure the [raw] data, and, as a consequence, were unable to verify research fraud conclusively' apparently not realising that fabricated data does not exist. Chandra later sued Harvey ${ }^{1}$.

Example 3. When the article that eventually appeared in Nutrition was submitted to the BMJ, as mentioned earlier, at least one reviewer had very serious doubts about it. Richard Smith, editor of the $B M J$, wrote to Memorial University about the problems ${ }^{12}$. Memorial replied that it 'was happy with Professor Chandra's research findings'. Smith wrote to Memorial again, asking if they had examined the raw data. Memorial replied that because Chandra had resigned and was uncooperative, it was unable to investigate.

Example 4. In January 2004, I contacted the Canadian Institutes of Health Research, the government agency that funded much of Chandra's research. I brought to their attention our critiques of Chandra's articles. In reply, the officer contacted told me 'I will be in touch'. Two years later, I have heard nothing further. It is unclear if the agency did anything.

In each case, contacting authorities did not lead to widely available information that would help everyone decide what to believe. I conclude that writing a letter to a journal is more effective than contacting authorities. The system would work better if it were easier to write such letters.

The problem with letters is the possibility of retaliation. Notably absent from Chandra's critics were active nutrition scientists. (An exception is Michael Meguid, the editor of Nutrition, who printed our letter ${ }^{6}$, wrote an accompanying editorial $^{19}$ supporting us, and eventually retracted Chandra's article ${ }^{17}$.) Susan Shenkin and her co-authors are psychologists. Kenneth Carpenter is retired. Sternberg and I are psychologists. The BMJ article was written by a staff writer. The BMJ and Lancet editors are not nutrition researchers. I believe that several active researchers suspected Chandra of fraud, but did nothing - presumably for fear of retaliation.

My suggestion is simple: allow anonymous letters. If these letters were judged by the editors or peer review to be reasonable, they would be published. The person criticised would of course be allowed to reply.

The Wisdom of Crowds ${ }^{20}$ describes a wealth of studies in which many people independently answered a difficult question based on accurate but highly incomplete information. An average of their answers was surprisingly accurate.

A scientific reputation is a kind of average. It does not exist in any one place; it exists in the minds of the many scientists in one's field. To publish a critique in a journal is to provide one's scientific community with more information relevant to the reputation of the person criticised. The studies described in The Wisdom of Crowds make it reasonable to assume that the new information will help, not hurt - that the reputation of the person whose work is criticised will change in the appropriate direction.

Seth Roberts

Department of Psychology

University of California

Berkeley CA 94720, USA

Email: twoutopias@gmail.com

\section{References}

1 O'Neill-Yates C. The secret life of Dr. Chandra. The National (Canada) [three features], 31 January-2 February 2006. Available at http://www.cbc.ca/national/news/chandra

2 Chandra R. Effect of vitamin and trace-element supplementation on cognitive function in elderly subjects. Nutrition 2001; 17: 709-12.

3 Shenkin S, Whiteman C, Pattie A, Deary I. Supplementation and the elderly: dramatic results? Nutrition 2002; 18: 364.

4 Chandra R. Response to comments of Shenkin et al. Nutrition 2002; 18: 364-5.

5 Brody J. Nutrition a key to better health for the elderly. New York Times, 21 August 2001. Available at www.nytimes.com

6 Roberts S, Sternberg S. Do nutritional supplements improve cognitive function in the elderly? Nutrition 2003; 19: 976-80.

7 Chandra R. Can nutritional supplements improve functional outcome in the elderly? Nutrition 2003; 19: 978-80.

8 Chandra R. Effect of vitamin and trace-element supplements on immune responses and infection in elderly subjects. Lancet 1992; 340: 1124-7.

9 Carpenter K, Roberts S, Sternberg S. Nutrition and immune function: a 1992 report. Lancet 2003; 361: 2247.

10 Chandra R. Response to comments of Carpenter et al. Lancet 2003; 361: 2247-8.

11 White C. Three journals raise doubts on validity of Canadian studies. British Medical Journal 2004; 328: 67. Available at www.bmj.com

12 Chandra R. Validity of Canadian studies: author's response. British Medical Journal 2004; 328: 465. Available at www.bmj.com

13 Mahoney J. Leading vitamin scientist faces fire over data. Globe and Mail, 11 December 2003.

14 Brody J. A top scientist's research is under attack. New York Times, 6 May 2004. Available at www.nytimes.com

15 Walsh N. Questions continue over research claims. $C B C$ News, 10 June 2004. Available at http://www.cbc.ca/nl/ story/nf_chandra_20040610.html

16 Walsh N. Chandra documentary. The Current (Canada), 10 June 2004. Available at http://www.cbc.ca/thecurrent/2004/ 200406/20040610.html

17 Meguid M. Retraction. Nutrition 2005; 21: 286.

18 Memorial University of Newfoundland. Statement from Memorial University of Newfoundland re: Dr. Ranjit Chandra and research integrity, 3 February 2006. Available at www.mun.ca

19 Meguid M, Shenkin A. Introduction: nutritional supplements and the quest to improve human performance - the need for the strictest standards and rigor when reporting clinical trials. Nutrition 2003; 19: 955-6.

20 Suroweicki J. The Wisdom of Crowds. New York: Random House, 2004. 